$\underline{\text { Research Article }}$

\title{
I've booked you a place, good luck: Applying behavioral science to improve attendance at high-impact job recruitment events
}

\section{Michael Sanders*, Elspeth Kirkman*}

\begin{abstract}
Finding a job, especially in a recovering or uncertain economy, is challenging. Jobseekers Allowance (JSA) welfare benefit claimants in the United Kingdom have many competing options available to them in terms of how they direct their efforts in looking for work. Jobcentres, the organizations that support job seekers, have very strong links to the labor market and often run recruitment events in direct partnership with large employers seeking to hire in bulk. Attendance at these events, or any other specific job search activity, is typically low. This article reports the results of a randomized control trial designed to test the effectiveness of mobile phone text messaging in compelling jobseekers to attend such events. Tailored text messages are found to significantly increase the likelihood of attendance. We find text messages to be particularly effective when they seek to induce reciprocity and address low morale in the recipient.
\end{abstract}

Keywords: Labor market, Employment, Field experiment, Reciprocity, Personalization

Supplements: $\underline{\text { Open data, }}$ Open materials

$\mathrm{U}$ nemployment is among the largest problems facing most western societies. In the aftermath of the 'great recession' unemployment across the developing world has been slow to recover, with much of the developed world yet to reach pre-2008 levels.

This problem is costly to unemployed individuals and society. Governments are paying unemployment benefits to more people, for longer, and hysteresis is dampening productivity. As well as these shorter-term consequences, long term impacts may be even greater. Gregg (2001) and Macmillan (2011) find considerable evidence of employment "scarring,"; a phenomenon whereby people (particularly young people) who experience a spell of unemployment due to a crisis are more likely to experience similar spells later in life.

* The Behavioral Insights Team, London, the U.K.

Address correspondence to Michael Sanders at (michael.t.sanders@,kcl.ac.uk)

Copyright: (c) 2019. The authors license this article under the terms of the Creative Commons Attribution 4.0 International License.
There exist many different theoretical models of employment. As a basis for this experiment, we assume some validity in models, such as Saks (2006) and Meyer (1990), that posit job search activity is a component of the production function of employment, and that more productive work search (for example, attending specific recruitment events where some participants will almost certainly gain employment) is key to finding work faster.

In this study, we present the results of a randomized controlled trial designed to test the effectiveness of mobile phone text messaging in compelling jobseekers registered at Bedford Jobcentre in the UK to attend specific recruitment events. Such events are run by Jobcentre Plus (in Bedford and elsewhere) in partnership with large employers seeking to hire several staff at once. These arrangements are generally exclusive, meaning only those invited by the Jobcentre are in the applicant pool. Although we do not have data on who was hired in our study, it seems reasonable to suppose that an increase in attendance might lead to an increase in employment. This is not, however, a necessary condition: even if job search 
activity of the type we study is not useful, the implications of our study suggest that the interventions studied could be directed to other, perhaps more effective, behaviors.

\section{Study Context}

This study's sample consisted of Jobseeker's Allowance (JSA) claimants accessing employment services at Bedford Jobcentre. Jobcentre Plus operates local Jobcentres across the United Kingdom. Jobcentres have two functions relevant to this trial: (1) to link their clients to employment opportunities locally; (2) to determine whether claimants are complying with the work search requirements for receiving JSA.

To understand the implementation and theory of change associated with this trial some context on the process is required. First, when jobseekers enroll at Bedford Jobcentre, they are assigned an Advisor who they will see each time they attend. This Advisor will document information on the claimant and their work skills, including tagging their record with Standard Occupational Classification (SOC) codes to describe these skills. Attendance at the Jobcentre typically involves giving this Advisor evidence to verify job search activity in the weeks (typically two) since the last appointment. If the claimant cannot show sufficient evidence, the Advisor can enact sanctions. Receipt of JSA is conditioned on demonstrating compliance at these appointments. As such, claimants usually know their Advisor by name, they may have a personal rapport, and there is a clear role each party plays in their relationship.

Second, some information on the events themselves: Jobcentres have direct relationships with the local labor market which often make them the partner of choice for finding employees to fill many roles quickly - for example, if a new factory or super market opens. Jobcentres select claimants to invite to these events based on whether their 'standard occupational classification' (SOC) code matches the skills required by the employer. All eligible claimants are then sent an SMS message inviting them to attend the event. Attendance at these mass recruitment events, in contrast to many other types of job search activity, is not mandatory. Unless the claimant had an appointment with their Advisor very recently it is likely that text message is the only way they might hear about such an event. The messages typically sent (the control in our experiment) do not indicate anything beyond basic information about the role(s) or the event.

\section{Literature Review}

Although we were not able to conduct in depth research with claimants, conversations with Jobcentre staff helped us to identify potential barriers to attendance and formulate a few working hypotheses as to how jobseekers determine whether to attend an event, what barriers suppress turnout and what might be done to overcome them. First, claimants may ignore a text message, assume it was sent in error, or even think it is not genuine if they do not recognize the sender number. As such, we speculate that signaling the message is legitimate, directed, and purposeful may help. Second, we heard that claimants often fixate on what they know to be mandatory job search activities; since this activity is not mandatory it may not be sufficiently compelling. We speculate that including an official signal of endorsement may make this opportunity seem more compelling. Third, claimants may not appreciate that the Jobcentre staff is actively working to help them find employment through these events. We speculate that drawing attention to the administrative effort of planning may drive increased attendance. Finally, claimants may be demoralized as a result of unemployment and may think their efforts will not be successful. Including morale boosting language that seeks to overcome a shrinking locus of control may, we speculate, boost attendance.

With these four hypotheses in mind, we reviewed the behavioral science literature to inform the design of our messaging interventions. The resulting treatments build on one another with each including the same language as the last. As such, the study should be read as a test of the combination of these treatments and not as a clean test of each potential mechanism. Below we discuss both the use of the texting channel and the evidence base on how to address the barriers to attendance we observed.

\section{Text Messages as a Call to Action}

A strong research precedent suggests that text messages can provide a high impact, low cost, channel through which to galvanize action. Text messages have been trialed in a variety of domains such as repayment of court fines (Haynes et al., 2013), loan repayment (Morten, Karlan, \& Zinman, 2013) and saving energy (Gleerup et al., 2010). Text 
messages were already used as one of the communication channels deployed by Bedford Jobcentre Plus to promote recruitment events of this nature.

\section{Using Personalization to Grab Attention and Boost Legitimacy}

Drawing on a well-established body of research, Haynes et al. (2013) demonstrate that text messages including the recipient's first name drive a 41 percent increase in the repayment amounts of court-ordered fines compared to texts without personalization.

\section{Adding the Advisor Name to Signal Official Endorsement}

Morten, Karlan, \& Zinman (2012) explore the effect of drawing attention to the relationship between loan recipient and loan officer on soliciting repayments via text message. Of the conditions they trial, "messages that mention the loan officer's name significantly, substantially, and robustly improve repayment rates relative to messages that mention the client's name and/or to the no-message control group" (p. 9). This is only true for borrowers who have already met their loan officer, implying that social connection explains the difference in results. In this experiment, we build on these findings by attempting to test the difference between elements of the Jobseeker/ Advisor altercast.

\section{Highlighting Effort to Induce Reciprocity and Signal that the Jobcentre Invests in These Opportunities}

Highlighting effort on the part of Jobcentre staff might change the decision calculus of the claimant since it signals that the staff consider these events sufficiently valuable to invest time in planning them. Beyond this, literature on the use of reciprocity unconditional gift giving or service by one party to another - suggests this may turn out to be an effective way to encourage a desired behavior (see Falk and Fischbacher, 2006). Both theoretical models and experimental results show that calling on social conventions of reciprocity is disproportionately effective when trying to get individuals to comply with a request. For example, an experiment into interventions that impact charitable donations by employees at a large bank showed that 11 percent of people given the small gift of a bag of sweets donated a day's salary compared to just 5 percent whose donation was solicited by the traditional awareness raising campaign tactics (Behavioural Insights Team, 2013). Field studies of reciprocity conducted to date (e.g., Behavioural Insights Team, 2013; Falk, 2007; Alpizar, Carlsson, \& Johansson-Stenman, 2008), aim to elicit reciprocity by the giving of physical gifts, such as sweets, fridge magnets and postcards. In this experiment, we consider whether gifting a service (the exertion of a small quantity of effort to book an appointment), can be similarly effective at motivating behavior.

\section{Evoking Luck to Overcome a Shrinking Locus of Control}

The literature suggests that job seekers with an internal locus of control conduct more work search activity than those who believe that their future outcomes are determined by external factors (e.g. Caliendo, Cobb-Clark, \& Uhlendorff, 2010). As such, targeting jobseekers with an external locus of control may help those less likely to attend to show up. Building on a body of research linking beliefs in luck to changes in action and behavior, Sagone et al. (2014) show that those with an external locus of control - in our domain, those who may be less likely to perform enough job search activity - have a stronger belief in the notion of "luck". In this experiment, we evoke the concept of luck as a means to increase the likelihood those with an external locus of control will take action.

\section{The Intervention}

Based on the literature review, we designed three new messages, each of which builds on the one before, to test against the control. The control is the standard language used in such recruitments prior to the experiment.

\section{Experimental Design}

We use a randomized control trial design to determine the effect of variations on a text message on attendance rates at specific recruitment events held by Bedford Jobcentre Plus. Randomization is conducted at the individual participant level, within each recruitment event separately, yielding randomization stratified by recruitment event. All participants $(n=1,224)$ were drawn from the pool of active JSA claimants at Bedford Jobcentre Plus. 
Table 1

Message Variants Used in the Experiment

\begin{tabular}{|c|c|}
\hline $\begin{array}{l}\text { Treatment } \\
\text { name }\end{array}$ & Message text (formulation, and example with additive changes in bold) \\
\hline Control & $\begin{array}{l}\text { Formulation: [number] new [type of job] are now available at [company]. Come to } \\
\text { Bedford Jobcentre on [date and time] and ask for [staff member name] to find out } \\
\text { more. } \\
\text { Example: } 8 \text { new Picker Packer jobs are now available at Pro FS. Come to Bedford } \\
\text { Jobcentre on Monday } 10 \text { June between 10am and } 4 p m \text { and ask for Sarah to find out more. }\end{array}$ \\
\hline $\begin{array}{l}\text { + Claimant } \\
\text { name }\end{array}$ & $\begin{array}{l}\text { Formulation: Hi [jobseeker name]. [number] new [type of job] are now available at } \\
\text { [company]. Come to Bedford Jobcentre on [date and time] and ask for [staff member } \\
\text { name] to find out more. } \\
\text { Example: Hi Elspeth, } 8 \text { new Picker Packer jobs are now available at Pro FS. Come to } \\
\text { Bedford Jobcentre on Monday } 10 \text { June between } 10 \text { am and } 4 \text { pm and ask for Sarah to find } \\
\text { out more. }\end{array}$ \\
\hline $\begin{array}{l}+ \text { Advisor } \\
\text { name }\end{array}$ & $\begin{array}{l}\text { Formulation: Hi [jobseeker name]. [number] new [type of job] are now available at } \\
\text { [company]. Come to Bedford Jobcentre on [date and time] and ask for [staff member } \\
\text { name] to find out more. [Advisor name] } \\
\text { Example: Hi Elspeth, } 8 \text { new Picker Packer jobs are now available at Pro FS. Come to } \\
\text { Bedford Jobcentre on Monday } 10 \text { June between } 10 \text { am and } 4 \text { pm and ask for Sarah to find } \\
\text { out more. Michael }\end{array}$ \\
\hline $\begin{array}{l}\text { + Reciprocity } \\
\text { \& Luck }\end{array}$ & $\begin{array}{l}\text { Formulation: Hi [jobseeker name]. [number] new [type of job] are now available at } \\
\text { [company]. Come to Bedford Jobcentre on [date and time] and ask for [staff member } \\
\text { name] to find out more. I've booked you a place. Good luck, [Advisor name] } \\
\text { Example: Hi Elspeth, } 8 \text { new Picker Packer jobs are now available at Pro FS. Come to } \\
\text { Bedford Jobcentre on Monday } 10 \text { June between } 10 \text { am and } 4 \text { pm and ask for Sarah to find } \\
\text { out more. I've booked you a place. Good luck, Michael }\end{array}$ \\
\hline
\end{tabular}

Participants were randomly assigned to receive one of the four intervention messages (coded zero to three). Each participant was part of the trial for one recruitment event only, so each participant appears in our data only once. If a participant is eligible for a second event, they were sent the same message as previously but excluded from the experiment and hence from the data that we received.

The study investigates the relationship between message variant and attendance rate at specific recruitment events. These events took place between May and December 2013 and attendance was measured based on a binary measure of attendance indicating whether the jobseeker showed up at any time during the recruitment session to which they were invited. Data were also returned on the success rate for delivery of messages, although we do not know whether a message that is delivered is ever opened.

As the sessions were for specific jobs, it was possible to identify suitable participants using information in the Jobcentre Plus database on their skills and suitability for the type of work (as denoted by their SOC code). Jobseekers identified in this way were then texted in the order that their records were returned by the system. The maximum number of text recipients per recruitment event was determined based on Jobcentre capacity, staff availability and an expected attendance rate. The upshot is that staff are available beyond likely demand, meaning they would be able to handle the recruitment even if 50 percent of those texted were to attend.

Owing to resource constraints, the same Jobcentre Plus staff member was responsible for 
sending the text messages and running the recruitment sessions. The procedure for ensuring the staff member remained blind to the treatment is documented in the Appendix.

\section{Results}

Data were analyzed in Stata version 12. Our data contain 1,224 observations of participants who were eligible to receive text messages as part of this trial. For each participant we observe their treatment assignment, the name of their Jobcentre advisor, and the details of the job they are invited to apply for, including the job title, the employer, and the number of posts available. For variables relating to the job role and their advisor, we conduct $\mathrm{Chi}^{\wedge} 2$ tests of balance, and find no significant imbalance between these variables and treatment assignment for job title $(\mathrm{p}=0.142)$, the employer $(p=0.22)$, or advisor name $(p=0.77)$. There is significant imbalance on the number of jobs available, driven by one role advertised to 3 participants only with 200 potential jobs available. As well as the text message they were sent, we observe whether they received the text message (i.e., whether the phone number held by DWP for them is correct). In total, roughly 25 percent of the text reported in column 5 of table 2 . One condition (Advisor name) has significantly lower failure than the control, but the other arms are not significantly different and do not differ significantly from eachother in their failure rate. Finally, our data contain information about the session to which they were assigned, and whether they attended that session.

Table 2 below reports the results of a set of regression analyses. Column 1 shows an OLS (linear probability) model regressing attendance on treatment variables, with control the omitted category. Column 2 presents marginal effects from a logistic regression with the same specification. Column 3 shows a two staged OLS regression, with the first stage regressing receipt of messages on treatment variables and the second stage regressing attendance on predictions from first stage. Column 4 replicates column 1 , restricting the sample only to participants who did not receive messages, as a manipulation check.

Column 1 in the table shows Intention to Treat (ITT) estimates for the full sample, that is, for all participants whom the Jobcentre attempted to reach in each treatment group. We identify a strong positive impact on attendance in the final,

Table 2

Regression Estimates of Treatment Effects

\begin{tabular}{|c|c|c|c|c|c|}
\hline & \multicolumn{2}{|c|}{ Analysis } & \multirow[b]{2}{*}{$\begin{array}{c}\text { (3) } \\
\text { Attendance } \\
\text { (2SLS) }\end{array}$} & \multirow[b]{2}{*}{$\begin{array}{c}\text { (4) } \\
\text { Attendance } \\
\text { (DACE) }\end{array}$} & \multirow[b]{2}{*}{$\begin{array}{c}(5) \\
\text { Failure } \\
\text { (Exogeneity } \\
\text { Check) }\end{array}$} \\
\hline & $\begin{array}{c}(1) \\
\text { Attendance } \\
\text { (OLS ITT) }\end{array}$ & $\begin{array}{c}\text { (2) } \\
\text { Attendance } \\
\text { (Logistic } \\
\text { ITT) }\end{array}$ & & & \\
\hline + Claimant Name & $\begin{array}{c}0.043 \\
(0.032)\end{array}$ & $\begin{array}{c}0.059 \\
(0.041)\end{array}$ & $\begin{array}{c}0.055 \\
(0.040)\end{array}$ & $\begin{array}{c}0.053 \\
(0.059)\end{array}$ & $\begin{array}{l}-0.069 \\
(0.036)\end{array}$ \\
\hline + Advisor Name & $\begin{array}{l}0.069^{*} \\
(0.031)\end{array}$ & $\begin{array}{l}0.090^{*} \\
(0.040)\end{array}$ & $\begin{array}{l}0.089^{*} \\
(0.039)\end{array}$ & $\begin{array}{c}0.020 \\
(0.057)\end{array}$ & $\begin{array}{l}-0.070^{*} \\
(0.035)\end{array}$ \\
\hline + Reciprocity \& Luck & $\begin{array}{c}0.163^{* * *} \\
(0.030)\end{array}$ & $\begin{array}{c}0.188^{* * *} \\
(0.41)\end{array}$ & $\begin{array}{c}0.220^{* * *} \\
(0.041)\end{array}$ & $\begin{array}{c}0.042 \\
(0.054)\end{array}$ & $\begin{array}{l}-0.035 \\
(0.035)\end{array}$ \\
\hline Constant & $\begin{array}{c}0.105^{* * *} \\
(0.022)\end{array}$ & $\begin{array}{c}0.117 * * * \\
(0.022)\end{array}$ & $\begin{array}{c}0.105^{* * *} \\
(0.022)\end{array}$ & $\begin{array}{l}0.119^{* *} \\
(0.039)\end{array}$ & $\begin{array}{c}0.295^{* * *} \\
(0.026)\end{array}$ \\
\hline
\end{tabular}

Notes: $* p<.05,{ }^{* *} p<.01,{ }^{* *} p<.001$ (two-tailed test). Standard Deviations appear in the parentheses below the means. $\mathrm{N}=1224$ (307 for column (4))

messages (307 participants) failed to be received. The rate of message failure between conditions is 
Table 3

Average Attendance and Confidence Intervals by Treatment

\begin{tabular}{lccc}
\hline & \multicolumn{3}{c}{ Regression Estimates } \\
\cline { 2 - 4 } & $\begin{array}{c}\text { Average } \\
\text { Attendance Rate }\end{array}$ & Lower Bound CI & Upper Bound CI \\
\hline Control & $10.5 \%$ & $6.9 \%$ & $14.1 \%$ \\
+ Claimant Name & $14.8 \%$ & $10.8 \%$ & $19.0 \%$ \\
+ Advisor Name & $17.4 \%$ & $13.2 \%$ & $21.6 \%$ \\
+ Reciprocity \& Luck & $26.8 \%$ & $22.2 \%$ & $31.5 \%$ \\
\hline
\end{tabular}

Reciprocity \& Luck, treatment. Table 3 reports average levels of attendance by treatment, and 95 percent confidence intervals around each. Reciprocity \& Luck performs significantly better than any of the other treatments. This finding is replicated in Table 2 using a logistic regression, shown in column 2 (marginal effects are presented). Results are not sensitive to excluding the role with 200 potential jobs described above.

Column 3 in Table 2 reports the results of a two-stage-least squares (2SLS) instrumental variables approach in which assignment to conditions is used as an instrument for whether participants received that message. As might have been predicted, this serves to enhance the size of the effect, to a 22 percentage point increase in attendance in the most successful treatment group.

One potential concern is that there may have been imbalance in randomization by chance, and so participants assigned to our treatments may have been more likely to attend than those in the control group even in the absence of treatment. To test this, in column (4) we conduct a "Defier Average Causal Effect" (DACE) model, which estimates whether treatment assignment had any effect on those individuals who did not receive a text message, owing to delivery failure. Since these individuals were not, in fact, treated, we should expect no significant impact on this group if randomization has been successful. We find that this is the case, with no significant impact of treatment assignment on outcomes (attendance) for this untreated group. Although treated groups are more likely to respond than untreated groups, this effect is highly insignificant ( $p>0.371$ ), and the ordering of these differences is not the same as among the ITT or 2SLS analyses. We are therefore content that randomization has been successful and that the differences observed between groups is a result of our treatments.

Finally, column (5) contains a further balance check to determine the success of randomization. In this specification, the dependent variable is whether a text message failed to be received-that is, whether treatment assignment (which should be exogenously applied) predicts failure to receive the text message. Here, we find that all treatment groups are slightly less likely to fail to receive a text than the control group. For all but treatment 2 this difference is insignificant. In treatment 2 , the difference is significant $(\mathrm{p}=0.046)$, however, the effect is not sufficient to lead us to question our primary results.

\section{Discussion}

It is worth being clear that the additive design of our treatments does not allow us to conclusively determine the most effective mechanism for boosting attendance. In other words, we cannot be sure whether the Reciprocity + Luck message would be most effective in the absence of bundling this language with that of the other treatments. Additionally, our conclusions about impact are limited since we were not able to obtain data on whether those who attended events were hired and, most importantly, whether it is likely those who attended because of our new messages were hired.

Nonetheless, the findings do show that varying the message sent to jobseekers influences their decision on whether to engage with a public service, and hence could be of broader relevance. One way to assess whether this finding is meaningful is to compare it to the effect of text messages in comparable domains. Whilst many other experiments use the medium of text message 
to affect action, such as attendance, we have not encountered studies that directly foreshadow what we investigate in this paper. Our study was designed to be powered to detect small effect sizes. Following Cohen (1988), the minimum detectable effect size in our study is a Cohen's $b$ of 0.22 . The results suggest that the effects of the two personalization treatments are similar in absolute and standardized size to those found in other text message studies, in particular Karlan et al. (2012), and Haynes et al. (2013). This implies a degree of generalizability, which could mean this approach would work equally well for other employmentrelated activities.

The effect of the Reciprocity \& Luck condition is somewhat larger than other effects observed in the literature. We see two likely explanations for this: first, this may relate to the difference in outcomes - in our case, attendance, while in Haynes et al. and Karlan et al. the probability of payment. Second, the treatment effectively bundles several mechanisms beyond those tested in other conditions. We also believe that further study to separate out elements of the mechanism, for example, testing the effect of the line "I've booked you a place, good luck!" without personalization, or disentangling the elements of reciprocity and luck, could be fruitful to ensure maximum effect is being achieved.

Beyond the mechanics of the study, we must pause to consider generalizability of the findings. First, this study was conducted during a recession, meaning that labour market conditions were not usual. Although this is likely to have an impact on the types of job search that are most fruitful, as well as the expected probability of getting a job, we believe that low cost methods to connect claimants to opportunities are likely to yield benefits (with the goal of shortening spells of unemployment) in any market. Second, we see applications for this approach in a range of other domains. From market failures (Madrian (2014)), to poverty alleviation (Bertrand \& Mullainathan (2004)), the use of behavioural tweaks to improve the impact of government intervention is well documented. While SMS reminders are just one way to intervene, they have exciting potential to address the real factors that weigh into decision making at the moment a decision is being made. Indeed, beyond the research we discuss previously, there is a body of evidence demonstrating the positive impact of SMS messages across the policy spectrum, from increasing voter turnout (see Dale \& Strauss (2009)), to smoking cessation (see Free et al. (2011)), to educational attainment (see Bergman (2015).

\section{Conclusion}

The objective of this study was to investigate the effects of variations on a text message on attendance rates. Our results show that the "reciprocity \& luck condition" (T3: "... I've booked you a place. Good luck..."), which includes the language of the other treatments, is significantly more effective than any other message in attracting participants, leading to an attendance rate of 26.8 percent compared to 10.5 percent in the control. Although the effect is not of the same magnitude, the authors also find that using the Jobseeker's first name and the name of their Advisor is powerful in prompting attendance. These findings are in line with our initial hypotheses.

\section{References}

Alpizar, F., Carlsson, F., \& Johansson-Stenman, O. (2008). Anonymity, reciprocity, and conformity: Evidence from voluntary contributions to a national park in Costa Rica. Journal of Public Economics, 92, 1047-1060.

Bergman, P. (2015). Parent-child information frictions and human capital investment: Evidence from a field experiment. Working Paper Available at https://ssrn.com/abstract $=2622034$

Bertrand, M., Mullainathan, S., \& Shafir, E. (2004). A behavioral-economics view of poverty. American Economic Review, 94(2), 419-423.
Bryan, C. J., Walton, G. M., Rogers, T., \& Dweck, C. S. (2011). Motivating voter turnout by invoking the self. Proceedings of the National Academy of Sciences, 108 , 12653-12656.

Caliendo, M., Cobb-Clark, D. A., \& Uhlendorff, A. (2015). Locus of control and job search strategies. Review of Economics and Statistics, 97(1), 88103.

Dale, A., \& Strauss, A. (2009). Don't forget to vote: text message reminders as a mobilization tool. American Journal of Political Science, 53(4), 787-804. 
Falk, A. (2007). Gift Exchange in the Field. Econometrics $75,1501-1511$

Falk, A., \& Fischbacher, U. (2006). A theory of reciprocity. Games and Economic Behavior, 54, 293-315

Free, C., et al. (2011). Smoking cessation support delivered via mobile phone text messaging (txt2stop): a single-blind, randomised trial. The Lancet, 378(9785), 49-55.

Gleerup, M. (2010), et al. The Effect of Feedback by Text Message (SMS) and Email on Household Electricity Consumption: Experimental Evidence. Energy Journal 31.3

Gregg, P. (2001). The impact of youth unemployment on adult unemployment in the NCDS. The economic journal, 111, 626-653.

Haynes, L. C., Green, D. P., Gallagher, R., John, P., \& Torgerson, D. J. (2013). Collection of Delinquent Fines: An Adaptive Randomized Trial to Assess the Effectiveness of Alternative Text Messages. Journal of Policy Analysis and Management, 32, 718-730

Madrian, B. C. (2014). Applying insights from behavioral economics to policy design. Annu. Rev. Econ., 6(1), 663-688.

Macmillan, L. (2011). Measuring the intergenerational correlation of worklessness. Centre for Market and Public Organisation.

Meyer, Bruce D, (1990). Unemployment Insurance and Unemployment Spells. Econometrica, Econometric Society, vol. 58(4), pages 757-782, July.
Karlan, D., Morten, M., \& Zinman, J. (2012). A personal touch: Text messaging for loan repayment (No. w17952). National Bureau of Economic Research.

Pratkanis, A. R., \& Gliner, M. D. (2004). And when shall a little child lead them? Evidence for an altercasting theory of source credibility. Current Psychology, 23, 279304

Pratkanis, A. R. (2007). Social influence analysis: An index of tactics. The science of social influence: Advances and future progress, 17-82

Sagone, E., \& De Caroli, M. E. (2014). Locus of control and beliefs about superstition and luck in adolescents: What's their relationship?. Procedia-Social and Behavioral Sciences, 140, 318-323.

Team, B. I. (2013). Applying behavioural insights to charitable giving. London: Cabinet Office

Hogg, M. A., \& Terry, D. I. (2000). Social identity and self-categorization processes in organizational contexts. Academy of management review, 25(1), 121-140.

Saks, A. M. (2006). Multiple predictors and criteria of job search success. Journal of Vocational Behavior, 68(3), 400-415.

Tiggemann, M., \& Winefield, A. H. (1984). The effects of unemployment on the mood, self-esteem, locus of control, and depressive affect of school-leavers. Journal of occupational Psychology, 57, 33-42

Weinstein, E. A., \& Deutschberger, P. (1963). Some dimensions of altercasting. Sociometry, 454-466

\section{Appendix}

\section{Appendix A. Detail on Blinded Messaging Procedure}

When a recruitment is initiated the following procedure is put in place:

1. Once participants are identified using SOC codes, their information (first name, last name, advisor name, phone number, national insurance number) is entered into a data template designed by the researchers.

2. The Jobcentre Plus staff member responsible for data entry then runs a code written by the researchers (by pressing a button), which handles the randomization and data preparation as follows:

i. Assigns each participant to one of the four trials arms at random.

ii. Uses a conditional message formula to generate the text to be sent based on personal details and trial arm assignment.

iii. Replaces the National Insurance number with a unique identifier (so that the information can be shared with the research team without the need for personal data sharing).

iv. Creates two visible sheets: one with the text message and phone numbers only (plus instructions on the day and time the messages should be set to send at, to control for variations between sessions), which can be pasted into the text messaging machine; one with the names of all participants, their unique ID number and blank columns to record attendance plus any comments.

v. Creates a hidden (password protected) sheet that only the research team can access, which contains unique identification numbers plus the text condition for each participant. 
The text messages are then sent using the first of the sheets and the attendance of participants is recorded on the day(s) of the session(s) using the second. At the end of each recruitment episode, the Jobcentre staff send the attendance sheet and the hidden sheet (which is contained in the same document and remains uneditable without the password) to the researchers along with a delivery report for all SMS text messages. The hidden data is decrypted and the unique identifiers are then used to match attendance to text condition. As an assurance exercise, the delivery records are checked to ensure that failure is consistent across conditions (indicating that the randomization has been performed effectively) and that a sufficient number of texts were delivered. 